\title{
Research on the Work Mode of University Students under the New Media Environment
}

\author{
Dong-xu Liu', Zhao Liu², Ji-peng Zhao ${ }^{1}$ \\ ${ }^{1}$ Department of Economic Management, North China Electric Power University, Baoding, China \\ ${ }^{2}$ Financial Synergy Innovation of Science and Technology Center in Hebei Province, Hebei Finance \\ University, Baoding, China
}

Keywords: New media, influence, college students, work mode

\begin{abstract}
In recent years, with the rapid development of digital technology, new media has been used by more and more people, which affects people's ideas, value orientation and behavior, etc.. The contemporary university students' thought is open, and they have intense curiosity to new things, at the same time they also have very strong accepting ability. Therefore, the impact of new media on college students is the most profound, meanwhile it brings new opportunities and challenges to the work of college students. In this paper, the concept and characteristics of new media, the opportunities and challenges brought by the new media, as well as working model innovation under new media environment were talked, finally, it explored the new mode of student work to adapt to the new media environment.
\end{abstract}

\section{The Concept and Characteristics of New Media}

The term "new media" was first introduced by Gold Mark, director of the Columbia Institute of radio and television network technology in 1967. New media is a new form of media developed after the traditional media such as newspapers, radio, television and so on, including digital TV, mobile phone media and network media. Based on digital technology and network technology, new media provides information and entertainment services to users through the Internet, broadband LAN, wireless communication network, satellite channels, as well as computer, mobile phone, digital TV and other terminal, so the new media is also known as the digital media. At the same time, the new media is a changing concept with time, compared to the "old" media, new media is a new thing, such as the Internet; meanwhile the forms of old and new combination can be also used, such as electronic books, which is the formation of product that paper media cater to the characteristics of consumer groups. Compared with the traditional media, the new media has its own characteristics, with its unique advantages to cover all aspects of life, it radically changed the life and study of college students.

First, the new media is instant. The new media overcome the restrictions of traditional media in time and space, and it breaks the geographical area and time limit through the Internet, mobile phone and other forms, so that the public can receive and publish information whenever and wherever possible, then the instant dissemination of information is realized.

Second, the new media has a diversity of forms. In new media environment, the one-way mode of traditional media information transmission is broken, the public has become the active recipient of the information and the communicator, rather than passive recipients. The transformation of the public identity not only enhance the autonomy of information reception, but also makes the content of the new media become richer and richer, at the same time makes its' forms more and more diverse .

Third, the new media is interactive. It is a medium for people to communicate and interact, and the most important feature of it is interaction. This interaction is reflected in people's expression of their views through social communication software, e-mail, forums and other forms, and a more flexible and effective real-time interaction is achieved by communicating with others. This way of communication 
not only can reduce the exchange cost, but also make the collection and release of information becomes more simple and feasible.

Fourth, the new media has the characteristics of equality and virtualization. No matter what kind of career people engage in, what kind of status, you can use the new media equally, and become the publisher and the audience of information. In that open environment, anonymously can communicate with others equally, and speak freely without psychological burden.

\section{Advantages of New Media Applied to Students Work}

The openness of the new media provides a broader platform for students work. For college students, they can break through the limited resources of the school, and obtain the necessary knowledge and information whenever and wherever through mobile phones, computer networks and other new media. The student workers can make full use of new media' rich forms of expression to release the content which are helpful for students' growing up, and provide services for students, as well as promote the school's latest policy, meanwhile provide an open platform for the work of College students.

The variety of new media is helpful to improve students' working style. Most of the traditional mode of education take the classroom and the textbooks as the center, which carry out the work of student management by means of instillation theory, for the students, this pattern puts them in a passive position, which is regardless of their acceptance and understanding ability. With the continuous change of education concepts, the application of new media such as WeChat micro-blog, has become new carriers of student work, and that provides the exchange platform for the teachers and students, and students workers can make more directly and more accurate understanding of the students' psychological status and ideological trends. For example, they can understand the thoughts by browsing students' recent micro-blog, WeChat circle of friends and the latest trends of QQ released. They can push notifications or send phone messages via public numbers, so that students can understand the relevant documents in a timely manner. The diversity of new media provides a convenient platform for students work, which is helpful to improve students' working mode.

The virtuality and equality of new media are helpful to enhance the effectiveness of student work. With the popularization and development of new media, new forms of information dissemination were produced, students can speak freely on the Internet, and they are able to express their opinions and ideas without revealing their identity. Student workers can narrow the distance with students with the use of new media technologies, and they can also understand students' inner and real thoughts, as well as grasp students' idea dynamic, also they can use new media to help students to troubleshoot doubts, learning to solve practical problems in work and life, and guide students to grow healthily.

\section{Challenges Brought by New Media to Students}

The openness and diversity of new media affect the values of college students. The new media have the characteristics of rich information capacity, high degree of information sharing, quickly interactive spread, and so on. Students can get a lot of information in the shortest time, but most of them are not screened so that many unhealthy and negative content may be contained. Due to the lack of accurate selection of information, students will get information to spread again, and that cause the bad information flooding spread, thus that have a negative impact on positive education.

New media's virtual and interactive influence on the psychological health of college students. In daily life, students use the new media to interact in the network which can express their feelings in a bad mood. At the same time, the new media will be used by some people with ulterior motives to get rid of social ethics and shackles and ignoring social responsibility. Some students are addicted to the Internet who are indifference on at home and abroad events and what happened around him. And they are also indifference to the students around. It is easy to produce the psychological problems such as 
autism, tension, escape from reality, which affects the mental health development and even affects to establish good interpersonal relationship with others. Sometimes it may arise a personality disorder and interpersonal obstacles.

The generalization and sharing of new media can affect the authority of the students. New media has the characteristics of fast propagation, wide coverage and anonymous communication. Such features lead students to express their opinions without exposing their identities. Such as views and opinions for the school policy and the teacher and their interests which can not be meet, These students can publish and disseminate all ideas anonymously through new media without restrictions. It results that the spread of the information is upside down in black and white and the amorality. So it creates unnecessary confusion and undermines the normal order of the campus And it also has the results in the lack of credibility of the school.

\section{The Innovation of Students' Work Mode in the New Media Environment}

The application of new media is used more and more widely in the society. It represents the forefront of current social science and technology development and also promotes social progress. The workers of university need adapt to the new characteristics of the times and actively use new media so they can innovate methods of work constantly and expand the work of thinking. The can strive to keep pace with the times and keep up with the trend of the times.

Correct View of the New Media, and Enhance the Ability of New Media Applications of Student Workers. The student workers should take a positive attitude to meet new media and can not blindly attention to the negative phenomena such as "bow", "internet addiction" which is generated by the dependence on new media. So they have the rejection of new media psychology. Instead, they should update their ideas, explore new methods of work, pay attention to the new the media, and constantly improve the application ability of new media. And they also should try to find new problems with new media technology and study of new problems so they can solve the new problems. So they can strive to build a team of student work which has high political quality and skilled in the use of new media technology so as to improve the students' work mode and promote the development of student work.

To Strengthen the Construction of New Media Network Platform and Change the Way of Communication between Teachers and Students. In the traditional work of students, students is passive recipients of education and lack of equal communication with teachers. In the process of education ignores the needs of students and impacts the autonomy, participation and creativity of students. The development of new media leads to that the form of education is more diversity, the education content is more abundant and the degree of openness is also greatly enhanced. Student workers can use the Internet to communicate with students equally and instead of individual education mode to two-way interactive mode. Through communication guides students correctly and can become their guide naturally. Through establishment of the class QQ group, Fetion group and micro-blog space can give full play to the positive role of new media influence and leading the students by positive thinking. At any time it is ready to release the positive energy of the articles, news or stories and timely push the important activities for schools, departments. It can enhance communication between teachers and students and improve students' collective sense of honor.

Improve Work Style, Improve Work Efficiency. Student workers should actively use all kinds of new media to carry out the work. First, by the establishment of WeChat group, WeChat, QQ group and other public platform which can issue a notice, announcement and file in the student, not only to enable students to quickly understand the school policy and related documents but also they can understand the life and study the dynamic of students, to grasp the ideological trend. They enable students to work without the limitation of time and space. Second, they can release positive information encourage students to share resources through public platform to enable students to learn new knowledge outside 
the classroom. Third, they can establish daily management platform for students such as the establishment of the student management department homepage. And the relevant documents is posted on the home page such as scholarship, leave registration form, the development of party members and other information. And It can provide convenience for the student management and service and improve work efficiency.

Strengthen the New Media Literacy of College Students, Play the Role of Supervision and Guidance of Public Opinion. New media environment requires college students to have a certain knowledge of information technology. Therefore, promoting the of new media literacy skills of student workers becomes an important means of achieving the scientific of student management team in colleges and it can encourage the strengthening of new media knowledge and grasp of the technology with new media. By using the advanced technology and ideas can better guide and educate the students that it can supervise of students of public opinion-oriented. the mainstream information can be released among the students so that students can obtain more comprehensive information to improve the students' ability which can improve distinguish between right and wrong. So students can establish a correct world outlook, outlook on life and values. In addition, we should also be good at using new media to solve all kinds of problems of students and to achieve the desired results.

\section{Conclusions}

With the emergence and development of new media, people's lives have changed dramatically. College students as the main force of the new media under the influence of new media is very big of learning and thought. On the college students' values formation stage they is easily misled by false information. Therefore, college student workers should grasp the psychological and behavioral characteristics of contemporary college students to break the traditional mode of operation and constantly improve their own quality. So they have a correct understanding of the new media to build a high quality team of new media work and guide the students to grow healthily.

\section{References}

[1] Lv, F., et al., Exploration on the innovation mode of university students' work based on the new media era.Journal of heilongjiang college of education, 2013. 32(3): p. 15-16.

[2] Fu, G., Research on the influence of new media on College Students' work and the Countermeasures.Jiangxi Normal University, 2014.

[3] Cao, P. G., Reflections on the work of college students in the new media environment.Journal of Ideological and theoretical education, 2012. 55(9): p. 120-127.

[4] $\mathrm{Mu}, \mathrm{H} . \mathrm{R}$, Research on the innovation of College Students' work mode in the new media era. Journal of Qiqihar University (Phi\& Soc Sci), 2016. 35(1): p. 149-151. 